\title{
A methodology to remove Stator Skew in Small-Medium Size Synchronous Generators via innovative damper cage designs
}

\author{
Stefano Nuzzo, Michael Galea, Senior Member, IEEE, Paolo Bolognesi, Member, IEEE, \\ Gaurang Vakil, Member, IEEE, Daniel Fallows, Chris Gerada, Senior Member, IEEE \\ and Neil Brown
}

\begin{abstract}
This paper proposes and investigates an innovative methodology that can have a significant impact on the market potential of wound field, small-medium size synchronous generators. The technique proposed here is aimed at removing the need for the traditional stator skewing that is so commonly used in synchronous generators to achieve acceptable values of voltage total harmonic distortion. To do this, a non-standard damper cage configuration is proposed that comprises modulation of the damper bars' positioning. An off-the-shelf, 400kVA generator is used as a benchmark machine. Its rotor is optimized and modified according to the proposed technique. The results of the final machine are then compared to the benchmark machine highlighting the excellent advantages that can be achieved through this technique. A full-scale prototype of the modified generator is then built to experimentally validate the concept. Finally, a detailed analysis on all the performance aspects of the prototype is done, to guarantee that the proposed technique has no negative impact whatsoever on the generator's performance.
\end{abstract}

Index Terms-Asymmetrical Windings, Circuital Modelling, Damper Windings, Efficiency, Genetic Algorithms, Modulated Bars, Optimizations, Power Quality, Skewing, Synchronous Generators, Total Harmonic Distortion.

\section{INTRODUCTION}

A $\mathrm{N}$ essential component for any electrical power generation and power system is the wound-field,

Manuscript received January 02, 2018; revised March 18, 2018 and July 2, 2018; accepted July 27, 2018.

S. Nuzzo, M. Galea, G. Vakil, D. Fallows and C. Gerada are with the Power Electronics, Machines and Control Group, University of Nottingham, Nottingham, UK (e-mail: stefano.nuzzo@nottingham.ac.uk).

P. Bolognesi is with the Electrical Machines, Power Electronics and Drives Group, University of Pisa, Pisa, Italy (e-mail: p.bolognesi@ieee.org)

M. Galea and C. Gerada are also with the Power Electronics, Machines and Control Group, University of Nottingham Ningbo, Ningbo, China (e-mail: michael.galea@nottingham.edu.cn).

N. Brown is with Cummins Power Generation, Peterborough, UK; (e-mail: neil.brown@cummins.com). synchronous generator (SG), which today still represents the most common method for reliable mechanical to electrical energy conversion. However, the ever-more stringent quality compliancy and grid-code standards [1], [2] are pushing the need for better power quality at all levels, including at component (SG) level [3]. When it comes to relatively low-tomedium rated wound-field SGs, the most common/popular methodologies employed to improve their power quality performance in terms of voltage total harmonic distortion (THD), include

1) Special designs of the rotor geometry, where the shape of the salient poles is structured to have a non-constant airgap, resulting in improved output waveform shapes. This is a very popular optimization design process in SGs [4].

2) Appropriate winding configurations aimed at improving the quality of the output waveforms [5], [6].

3) Skewing of the stator to mitigate the effects that the presence of slot openings induces in the form of highorder, parasitic harmonics on the airgap flux density and in turn, on the voltage waveform at the stator terminals of SGs. Usually an angular offset of one slot pitch along the axial length of the stator pack is used [6], [7].

4) Non-standard damper cage configurations, where recent studies have shown that moving the bars of the damper cage winding along the radial and/or tangential directions can improve the voltage THD in salient-pole SGs [8]. In [9], it has been proven that non-complete end-connections attenuate the "slot" harmonics. However, such techniques usually come at the cost of inducing more elevated currents (and thus losses) in this additional, rotor winding [10]. To circumvent this issue, an innovative technique has been proposed in [11], consisting in optimally tailoring the bars' position.

From all the above, the most common methodology for THD improvement is by far stator skewing. This technique and its THD benefits are well consolidated. However it does compromise the overall electromagnetic performance of the machine and most importantly it also results in a significant 
increase in manufacturing complexity and therefore manufacturing costs.

Although the concept of modulating the damper cage has been already proposed by [11] to address losses in salient-pole SGs, it must be noted that the $4 M V A$ machine investigated in [11] was an ideal vehicle to reduce the bar losses, as these present very high values due to the open-slot stator structure.

Considering the above, in this paper an optimal damper cage topology is found for a smaller platform, i.e. a $400 \mathrm{kVA}$ generator, and for a different objective, consisting in achieving an acceptable value of voltage THD without having to rely on the invasive skewing of the stator. Although international standards specify a THD limit of 5\% for generators [2], this works aims at achieving a THD less than $3 \%$, as the SG manufacturers believe that in the near future the power quality requirements and the nature of their customers' demands will be even more stringent than they are today. To achieve this objective, the methodology is expanded and updated with respect to [11]. Also, this paper presents the first known experimental validation of the proposed modulated bar technique when applied to classical SGs. To the authors' knowledge, no other existing work has proposed and validated such a technique as investigated in this work.

\section{THE PLATFORM}

As vehicle to test the proposed concept, an 'off-the-shelf' salient-pole $400 \mathrm{kVA}$ SG is considered, whose main parameters are given in Table I and which is shown in Fig. 1a. For the scope of this paper, this machine will be henceforth known as Machine A.

Important aspects of this machine which have a major impact on its voltage THD include 1) the salient poles (whose angular span is equal to $70^{\circ}$ ) are shaped to have a constant airgap thickness (i.e. $2 \mathrm{~mm}$ ) along their tangential development, 2) the ratio between the outer rotor and outer stator radii is equal to $0.7,3$ ) the ratio between the stator slot opening width and the minimum air-gap thickness is equal to $2.5,4)$ the stator winding has a double-layer structure, with 16 coils-perphase, 2 parallel circuits and a $2 / 3^{\text {rd }}$ short-pitching, 5) the stator is skewed by one slot pitch, 6) the damper bars are symmetrically displaced around the central axes of the poles, 7) the damper bar pitch is equal to $9^{\circ}$ and 8) the damper cage end connections are realized through press-plates laminations.

TABLE I

SYNCHRONOUS GENERATOR MAIN PARAMETERS

\begin{tabular}{|c|c|}
\hline Parameter & Value \\
\hline Rated Power & $400 \mathrm{kVA}$ \\
\hline Rated Voltage & $400 \mathrm{~V}$ \\
\hline Rated Frequency & $50 \mathrm{~Hz}$ \\
\hline Rated Power Factor & 0.8 \\
\hline Rotor Pole Number & 4 \\
\hline Stator Slot Number & 48 \\
\hline Damper Bar Number & 24 \\
\hline Outer Stator Diameter & $500 \mathrm{~mm}$ \\
\hline Axial length & $500 \mathrm{~mm}$ \\
\hline
\end{tabular}

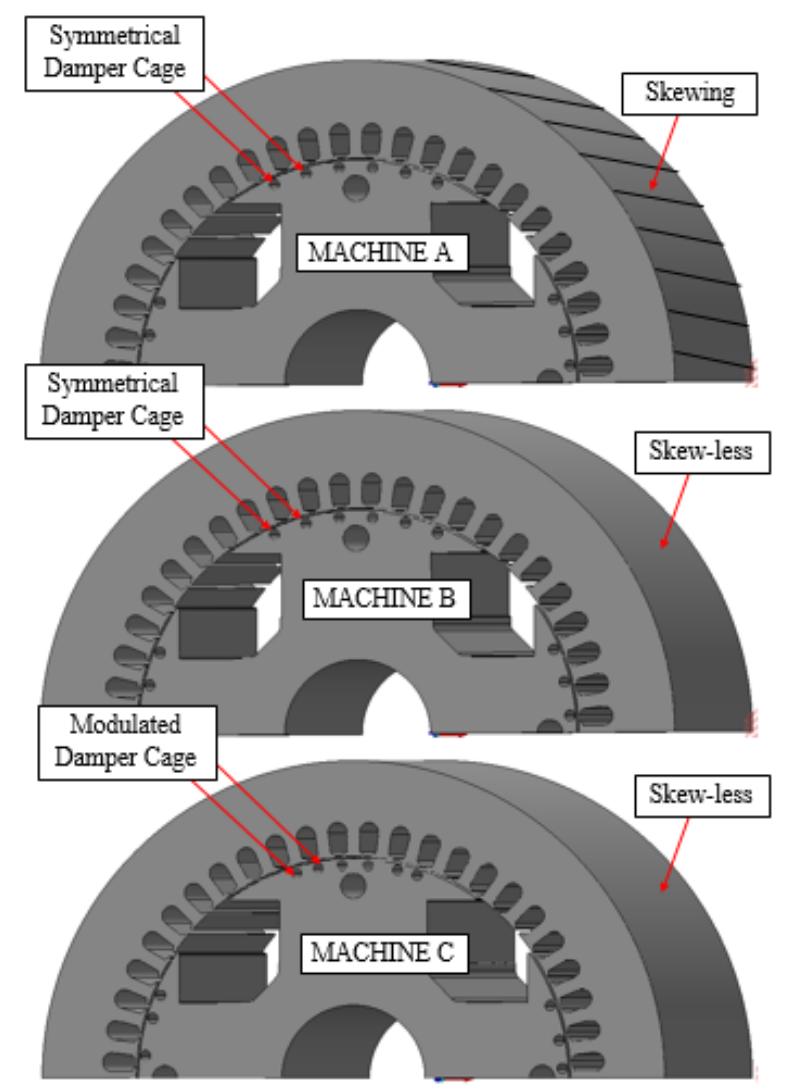

Fig. 1. a) Machine A - benchmark machine, consisting of a rotor equipped with symmetrically displaced damping bars and a skewed stator; b) Machine B - machine featured by a rotor equipped with symmetrically displaced damping bars and a skew-less stator; c) Machine C - optimal machine, consisting of a rotor equipped with a modulated damper cage and a skew-less stator.

\section{The InVEstigation Process}

To study the proposed concept on this platform, the investigation process that is used is described as follows:

1) Analytical and finite element (FE) models of Machine A are built and validated against experimental results. Although a 3-D FE analysis is the most accurate methodology to describe all the effects due to the stator skew, however today quite accurate (but fast) techniques, such as the single-slice 2-D method [12] can also be used. In fact it is this single slice method which is implemented in MagNet Infolytica environment for FE evaluations.

2) The stator skewing on the model of Machine $A$ is then removed to achieve a skew-less machine as shown in Fig. $1 \mathrm{~b}$, henceforth known as Machine B, which however still comprises the same rotor as Machine A. This machine is also modelled with accurate analytical and 2-D FE models and it is shown how the removal of the skew results in a considerable deterioration of the voltage THD.

3) Finally the proposed technique of modulating the damper bars is implemented. A detailed investigation via FE and genetic algorithm (GA) based methodologies is carried out to identify an optimal damper cage configuration that will justify (in terms of voltage THD values) the removal of skewing from the $400 \mathrm{kVA}$ SG. The model of this resulting machine is shown in Fig. 1c and will henceforth 
be known as Machine C. The modification on the rotor of the alternator is then physically implemented onto a fullscale prototype of the $400 \mathrm{kVA}$ SG for experimental validation.

The new prototype's performance (i.e. Machine C) is then compared to that of the original Machine A. This experimental work validates the proposed concept and proves that it is possible to remove the need for skew without compromising the steady state and transient performance of the machine.

\section{Performance of Machines A And B}

In order to fully understand the operation of the benchmark Machine A and the effects that stator skewing has on the SG, accurate FE models of Machine A and Machine B are built. Physical prototypes of these machines were also built. The detailed description of the development of these machines' models, as well as all the experimental activity done to validate these machines go beyond the scope of this paper and are therefore not given here, but can be found in [12] and [13]. Also, simulation and experimental results of these two machines are used in the comparisons against the performance of Machine $\mathrm{C}$, later in the paper.

However, considering the critical importance of the voltage THD for this work, then the relevant results for both machines are presented in Table II. Excellent similarity can be observed between the FE results and the experimentally-evaluated THD values of the no-load, line-to-line voltage for the two versions of the $400 k V A$ SG platform.

TABLE II

FE vs. EXPERIMENTAL RESULTS: No-LoAD Voltage THD

\begin{tabular}{|c|c|c|c|}
\hline Platform & Simulations & Experimental & Error \\
\hline Machine A & $1.26 \%$ & $1.34 \%$ & $5.97 \%$ \\
\hline Machine B & $5.58 \%$ & $5.94 \%$ & $6.11 \%$ \\
\hline
\end{tabular}

\section{THE PROPOSED CONCEPT}

Traditionally, the damper cage windings are fitted with bars that comprise a constant pitch and this is also the case of the alternator considered in this paper, as shown in Fig. 1a. The proposed concept consists in having a non-constant bar pitch, resulting in an unconventionally displaced winding, such as can be observed in Fig. 1c.

The aim of this section is that of recalling the general theory and the perceived advantages of the asymmetrical bar distribution. A comprehensive, theoretical insight of the modulated technique is given in [11], where equivalent functions describing the machine windings and geometrical features have been used to exploit a general expression of the inductance matrix [14]. In [11], it was found that both damper cage currents and voltage THD can be minimized by opportunely modifying the amplitude and phase harmonic components of the equivalent functions involved in the inductance expression, including those describing the damper winding. In [11], it was also shown that only the terms representing the mutual couplings between the armature winding and the rotor damper cage circuits can affect the terminal voltage shape.

Another way to get to the same results as in [11] is that of exploiting the term in (1) relative to the derivative of the flux vector $\bar{\varphi}$ with respect to time. In (1), the basic voltage equation derived from the classical equivalent circuit approach of electrical machines is provided. Here, the vector $\bar{i}$ is composed by the currents entering the machine phases, $\alpha$ is the angular position of rotor vs. stator and the matrices $R$ and $L$ represent the resistances and inductances characterising the machine, respectively.

Assuming that the damper cage is modelled as $b$ loops delimited by any couple of adjacent bars (where $b$ is the number of bars), the dimension of the system (1) is equal to $b+(3+1)=28$ for the considered generator platform. The exploitation of the flux vector derivative leads to obtain (2), where only the effects on one stator phase are considered (e.g. phase A). As the main target of this work is the no-load voltage THD, (2) is written upon the assumption that the stator phase currents are null. It can be observed that, apart from the mutual inductance $L_{A, f}$ between the stator phase and the field winding, the machine flux and thus the voltage of phase A are also dependent on the mutual inductances $L_{A, b 1}, L_{A, b 2}, \ldots, L_{A, b 24}$ between the phase $\mathrm{A}$ and all the 24 rotor loops relative to the damper cage.

$$
\begin{gathered}
\bar{v}(t)=R \cdot \bar{i}(t)+\frac{d \bar{\varphi}(t)}{d t}=R \cdot \bar{i}(t)+\frac{d(L(\alpha, \bar{i}) \cdot \bar{i}(t))}{d t} \\
\frac{d \varphi_{A}}{d t}=\frac{d}{d t}\left(L_{A, f} \cdot i_{f}+L_{A, b_{1}} \cdot i_{b_{1}}+L_{A, b_{2}} \cdot i_{b_{2}}+\ldots+L_{A, b_{24}} \cdot i_{b_{24}}\right)
\end{gathered}
$$

It is then clear that by changing the position of the damping bars, the relevant rotor loops link a different flux from that of the standard machine, as all the mutual inductances involved in (2) are modified by the bar repositioning. It is therefore perceived that there exists a particular, optimal pattern of these rotor loops that minimizes the interaction between the irregular damper pitch and the stator slot openings, potentially allowing to reduce the airgap parasitic harmonics and in turn the THD of the stator phase voltage.

\section{FiRst DEsigns AND Optimizations}

\section{A. The initial model}

The complex electromagnetic phenomena related to the damper winding of SGs have been extensively dealt with in literature. While the theoretical treatment of such aspects is still dominated by classical methods or approximated approaches [16], FE-based techniques represent today very accurate tools for the design and the analysis of such shortcircuited rotor winding. In fact, phenomena such as skin effect, high-order parasitic harmonics (e.g. the slot harmonics) and armature reaction effects on the damper cage, under any operating condition, can be modelled and analyzed in a very accurate way through the implementation of this numerical approach. Considering therefore that the damper cage 
behavior plays a key role for the purposes of this work (as it significantly affects the voltage THD in salient-pole SGs), then the optimal version of Machine $\mathrm{C}$ is developed via FE analysis, aided by a GA-based optimization tool. As a starting point, the FE models of Machine A and Machine B are taken. In Fig. 2, the details of the mesh used in the main air-gap and in the damping bars are shown. It can be observed that a) the air-gap is divided into four layers of equal thickness along the radial direction, b) each layer edge features a uniform node subdivision along the tangential direction and c) the damping bars are characterized by a dense mesh to capture any nonuniform current density effect possibly due to high-frequency phenomena. The mesh presented in Fig. 2 was achieved by adopting the "insensitivity of the solved quantity to further model refinement" criterion, i.e. by performing an iterative accuracy improvement process associated with a numerical sensitivity analysis.

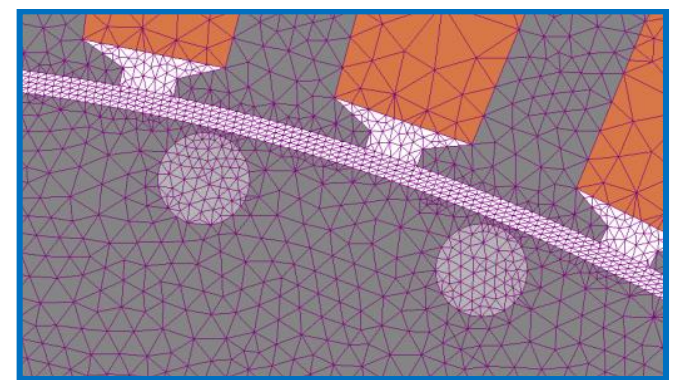

Fig. 2. Detail of the mesh used in air-gap and damping bars for FE analyses.

\section{B. The GA Optimization Tool}

Having validated the FE model of the benchmark Machine $\mathrm{A}$ and Machine B, this can then be used to analyze several damper cage topologies with the aim of meeting the stringent THD requirements without resorting to skewing. The chosen process to do this has the following major features:

1) Interface - the commercial, GA-based software ModeFrontier of Esteco is utilized for the optimization, due to its high flexibility in terms of interoperability with other applications (i.e. Matlab and MagNet of Infolytica) during the pre-processing, the solving and post-processing phases.

2) Input parameters - in order to take advantage of the periodicities of the machine and to reduce the computational resources associated with the FE and the GA analyses, only a quarter of the machine model is considered meaning that only the positions of the bars embedded in one salient pole are optimized, while the same positions are then used for the bars over the adjacent (not modelled) poles. Thus as the number of bars-per-pole is equal to 6 , this is also the number of the input variables, which are opportunely constrained in such a way that two consecutive bars never interfere with each other.

3) Optimization Strategy - the first phase is performed by using design of experiments (DoE) techniques [17]. Although these are used for many applications, here a DoE based on a random sequence is used to provide (to the optimization algorithm) an initial population of 50 individuals. The second phase of the procedure is that of performing a first exploration of the design space by using a multi-objective genetic-algorithm (MOGA), which is based on a scheduler designed for fast Pareto convergence and whose main features are described by [18]. In the end, a refinement is then carried out according to the results obtained in the first, preliminary phase (i.e. using the best solutions as initial population for a second round of optimizations).

4) Output variables - the objective is that of minimizing noload, line-to-line voltage THD and, at the same time, the damper cage loss. The main focus is however given to the voltage THD (set to $3 \%$ ), as for this paper this is the most important requirement to achieve. On the other hand, although previous studies [13] have shown that the damper cage does not represent a significant loss contributor in the $400 \mathrm{kVA} \mathrm{SG}$, it is essential to maintain losses below acceptable limits. Therefore, the loss threshold is taken as any value which is lower than the actual no-load damper cage loss found into the benchmark machine (i.e. $\approx 70 \mathrm{~W}$ ).

\section{Preliminary Results}

A generic machine scheme which highlights all the input variables used for the optimization study is given in Fig. 3. All the FE evaluations are carried out at no-load and the optimization results are plotted in Fig. 4. Considering that the simulated THD of the no-load voltage for Machine B is equal to $5.58 \%$ then from Fig. 4, it can be observed that improved solutions already exist, even if the bars are repositioned over one salient pole only (with the other poles copying the 'new' structure). However, for this case, the best solution in terms of voltage shape exhibits a THD of $\approx 4.6 \%$ while the improvement in losses is minimal. This confirms that to achieve feasible results in terms of both THD and losses, additional input variables need to be considered.

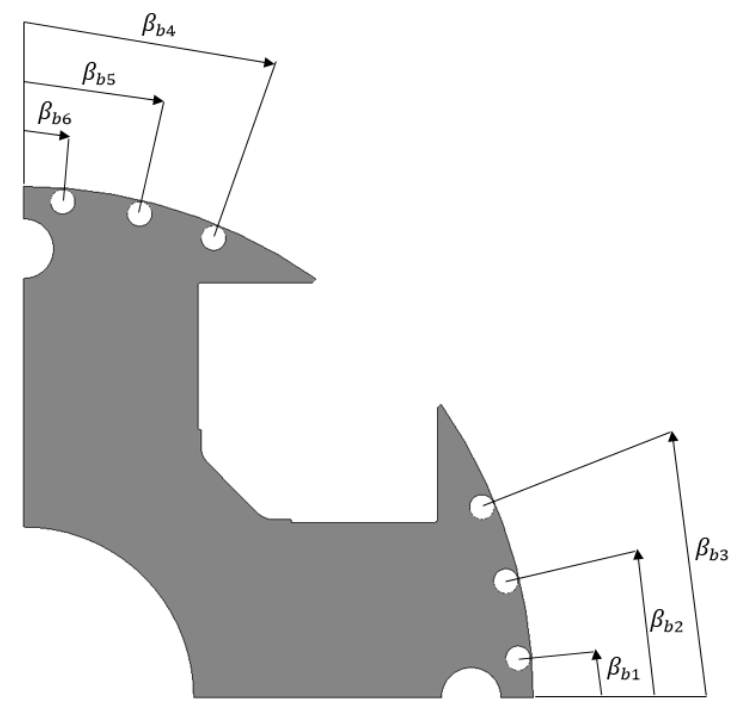

Fig. 3: Input parameters of the preliminary damper cage optimization study. 


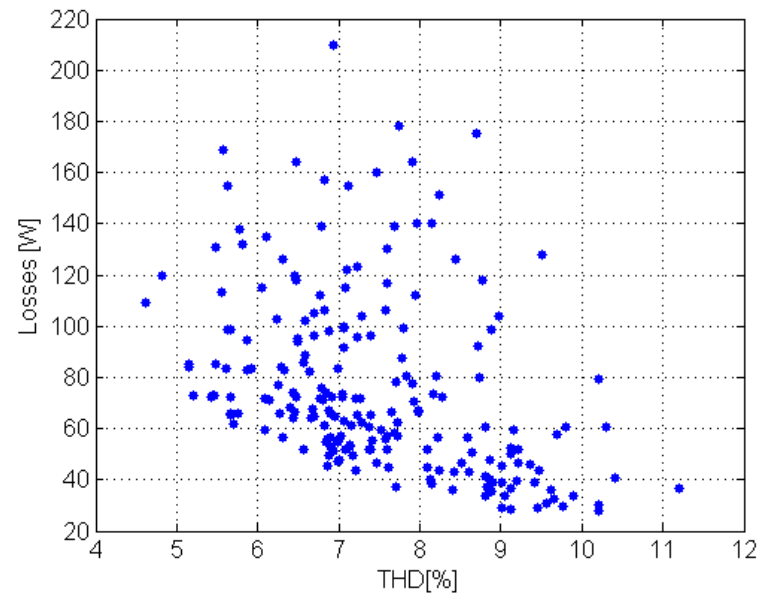

Fig. 4: Preliminary optimization results: damper cage loss vs. voltage THD.

\section{Further Remarks}

Before further going into the details of the investigation with modulation, it is important to consider that a number of "simpler" methods have already been investigated to address voltage THD requirements in SGs. As mentioned in Section I, one of the most common techniques consists in "shifting" the damper cage around the polar axes in alternating directions on each pole [15]. This design feature is commonly used today in industrial generators to remove the need for skew [8], [12]. However, the shifted damper cage methodology is mainly suitable for SGs featuring relatively low ratios between slot opening width and air-gap thickness (this typically occurs in medium-large SGs), where the "slotting effect" in the air-gap flux density is thus attenuated. In SGs where the ratios between slot opening width and air-gap thickness is relatively high (as in the alternator analyzed in this paper), the "slotting effect" can be significant and the shifted damper cage may be not sufficient to keep the THD below the $3 \%$ limit. This is proven by the work presented in [13], where the shifted damper cage technique is implemented on the same $400 \mathrm{kVA}$ platform analysed in this paper. Another important aspect to consider is that the shifted damper cage can lead to increased bar currents and thus ohmic losses in the bars when specific salient poles' profiles are adopted [11].

Amongst the "simpler" methods, also the effects on the voltage THD of the angular pole span and of the pole tips shape (i.e. having a non-constant air-gap thickness) have been investigated in [13] onto the same 400kVA SG. The results have shown that, although some slight improvements are possible, these are again not enough to allow the removal of stator skew.

Finally, in Section VI.C, the position of the bars embedded onto one salient pole has been modified with the aim of addressing losses and THD, showing that the best achieved solution does not comply with the objective of having a voltage THD lower than $3 \%$.

A summary aimed at comparing the effects of these methods is done. The 400kVA SG without skewing is considered and the results in terms of damper cage losses and voltage THD are compared in Table III. Machine B is used as benchmark. As already anticipated above, the THD improvements are not significant. Also, noticing the small values of the damper cage losses in relation to the SG rated power, it can be concluded that their impact on the machine efficiency can be neglected, justifying the main focus given to the THD minimization objective.

TABLE III

COMPARISON AMONGST TECHNIQUES - FE RESULTS

\begin{tabular}{|c|c|c|}
\hline Technique & No-load bar losses & THD \\
\hline Machine B & $71.2 W$ & $5.58 \%$ \\
\hline Non-constant air-gap & $42.7 \mathrm{~W}$ & $4.96 \%$ \\
\hline Optimal pole span & $70.8 \mathrm{~W}$ & $5.12 \%$ \\
\hline Shifted damper cage & $82.5 \mathrm{~W}$ & $4.05 \%$ \\
\hline Modulation over one pole & $110 \mathrm{~W}$ & $4.61 \%$ \\
\hline
\end{tabular}

\section{Machine C Optimization Results And Final PROPOSED SOLUTION}

As can be observed in Fig. 4 and Table III, by considering "standard techniques" and bar repositioning only over one salient pole, then the objective of having a voltage THD lower than 3\% is not achieved. Hence, a variant of the proposed technique is proposed, consisting in using additional degrees of freedom. A repositioning process for the bars distributed along two adjacent poles (one pole pair) is investigated, resulting in a doubled number (from 6 to 12) of input parameters. This variant allows for a significant increase in the number of possible combinations to consider, at the cost of increasing the required computational resources, as the minimum angular cross-section to model and solve via $\mathrm{FE}$ analysis now corresponds to $180^{\circ}$.

\section{A. Optimization Results}

The results obtained from the no-load optimization procedure with 12 variables are shown in Fig. 5. Few designs satisfy the objective constraints of $70 \mathrm{~W}$ and $3 \%$, for the losses and the THD respectively. These achievements are highlighted in the target area in Fig. 5. Among the best solutions, the one presenting the minimum THD and an acceptable value of damper cage loss is selected for the comparison with the actual design. The best performing solution is presented as a red dot in Fig. 5. Its rotor is illustrated in Fig. 6, where the particular pattern of the bar pitch modulation can be observed.

For the sake of completeness and for a clear understanding of the modulation mechanism, the final values of the 12 variables are listed in Table IV. Each variable is given as the angular distance between the original and the optimal positions of the damping bars, normalized over the original bar pitch (i.e. $9^{\circ}$ ). The sign of these variables is indicative of the direction of the bar repositioning with respect to the original location, having chosen the anticlockwise direction as the positive one. Referring to Fig. 1c, the variables are numbered from 1 to 12 in the anticlockwise direction. 


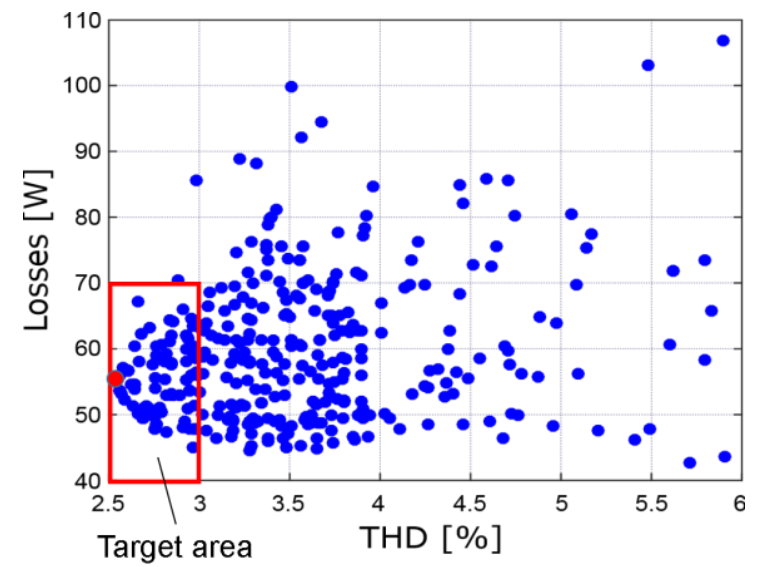

Fig. 5. Final optimization results: damper cage loss vs. voltage THD.

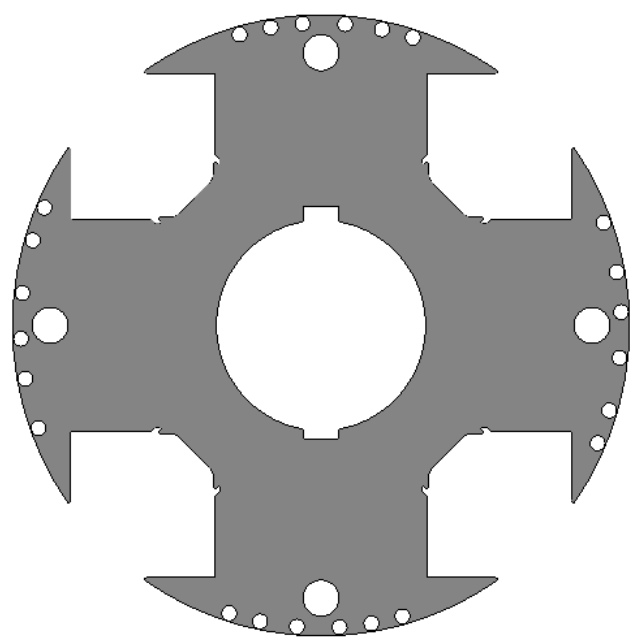

Fig. 6. Modulated damper cage: optimal pattern of the modulated bar pitch.

TABLE IV

OPtIMAL FINAL VALUES OF THE 12 INPUT OPTIMIZATION VARIABLES

\begin{tabular}{|c|c|c|c|}
\hline $\begin{array}{c}\text { Variable } \\
\text { Number }\end{array}$ & $\begin{array}{c}\text { Optimal } \\
\text { Value }\end{array}$ & $\begin{array}{c}\text { Variable } \\
\text { Number }\end{array}$ & $\begin{array}{c}\text { Optimal } \\
\text { Value }\end{array}$ \\
\hline 1 & -0.219 & 7 & -0.162 \\
\hline 2 & -0.371 & 8 & -0.428 \\
\hline 3 & -0.294 & 9 & -0.752 \\
\hline 4 & -0.523 & 10 & +0.049 \\
\hline 5 & -0.142 & 11 & +0.315 \\
\hline 6 & +0.047 & 12 & +0.181 \\
\hline
\end{tabular}

\section{B. Final Proposed Solution}

This optimal solution (Machine C) is compared at modelling-level in this section with Machine A and Machine $\mathrm{B}$. The comparison between Machine B and Machine C is the fairest one, as both present a skew-less stator and, therefore, it provides the real effectiveness of the proposed concept on the voltage waveform quality. However, since a manufacturer will mainly be interested in improvement over his current product, it is worth to show how the optimal machine compares with Machine A, as the latter represents the actual market product.

Firstly, the air-gap flux densities of the three machines are compared in Fig 7a. Here, the improvements achieved by
Machine C (with the modulated damper cage) over Machine B can be observed, whereas Machine A presents the "cleaner" flux density waveform due to the presence of skewing. However, in Fig. 7a, it can be noticed how a skew-less machine can achieve a flux density waveform similar to that of a skewed machine thanks to the implementation of a modulated damper cage. The relevant amplitude harmonic spectra shown in Fig. $7 \mathrm{~b}$ confirm that the modulated damper cage permits to significantly attenuate the slot harmonics. Other significant harmonic components (the $11^{\text {th }}$ above all) are also reduced. On the other hand, the asymmetries introduced by the different bar patterns between north and south poles lead to the introduction of even harmonics in the air-gap flux density of Machine $\mathrm{C}$, potentially resulting in higher parasitic shaft voltages [19]. Also, always referring to Fig. 7b, it can be noted that the air-gap flux density of Machine $\mathrm{C}$ presents an increased third harmonic in comparison with Machines A and $\mathrm{B}$, although triplen harmonics are overall reduced. However, given the $2 / 3$ short pitching layout of the armature winding, this does not come at the cost of compromising the achievement of the main objectives of this paper. In fact in Fig. 8, where the comparison between the no-load line-to-line voltage waveforms is provided, it can be observed that a more than halved value of the THD (from $5.58 \%$ to $2.56 \%$ ) is achieved by Machine $\mathrm{C}$ when compared with Machine B. In Fig. 8b, the comparison in terms of amplitude harmonic spectrum is also provided, confirming that the THD improvement is mainly due to the heavy attenuation of the groups of slotting harmonics, as highlighted in green in the same figure, where the amplitudes (on the y-axis) are provided in percentage of the fundamental harmonic (not shown in the graph).

The same comparison is carried out between Machine A and Machine C. In Fig. 9, it can be observed how Machine A presents a "cleaner" voltage shape than the optimal machine, with a THD $=1.26 \%$. This is expected, as the skewing has the effect of almost eliminating the slotting harmonics.
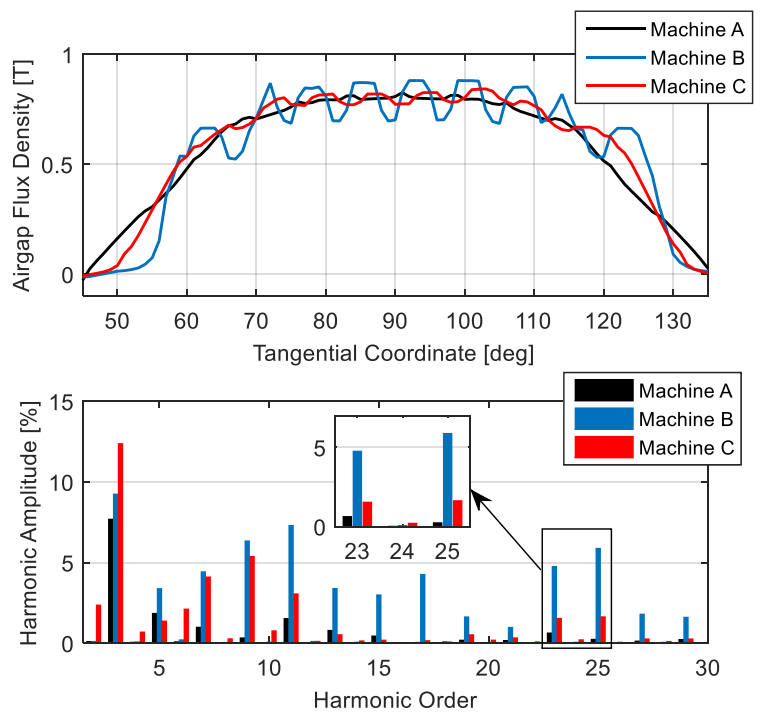

Fig. 7. Effects of modulation on the air-gap flux density - comparison between the three machines: a) flux density waveforms b) flux density harmonic spectra, with zoom on the first group of slot harmonics. 

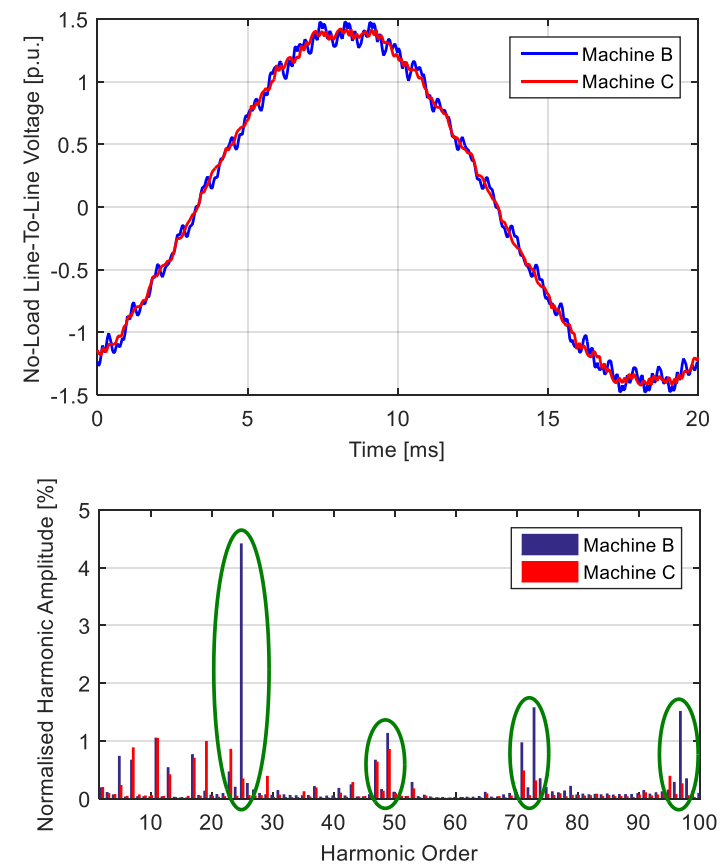

Fig. 8. Effects of modulation on the no-load voltage - comparison between Machine A and Machine B: a) voltage waveforms, b) voltage harmonic spectra.

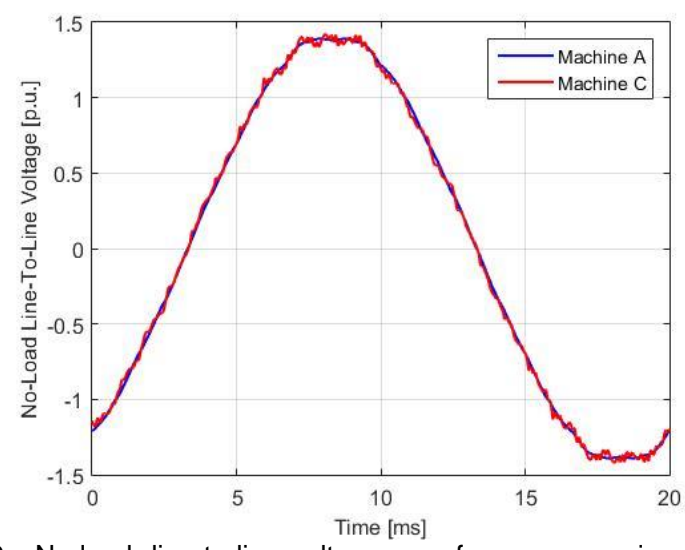

Fig. 9. No-load, line-to-line voltage waveforms: comparison between Machine $\mathrm{A}$ and Machine $\mathrm{C}$.

A summary of the comparison amongst the three topologies is shown in Table V, where the voltage THD as well as the damper cage loss at no-load operation are compared. The benchmark Machine A, still achieves a lower THD value than the proposed Machine $\mathrm{C}$, however it is important to note that Machine C complies with the set target of less than 3\% THD. In terms of losses, it can be concluded that Machine $\mathrm{C}$ achieves a reduction of $1.58 \%$ and $21.6 \%$ at no-load, respectively with respect to Machine A and Machine B.

TABLE V

COMPARISON AMONGST THE THREE CASE STUdIES - FE RESUltS

\begin{tabular}{|c|c|c|}
\hline Machine Topology & No-load bar losses & THD \\
\hline Machine A & $56.8 \mathrm{~W}$ & $1.26 \%$ \\
\hline Machine B & $71.3 \mathrm{~W}$ & $5.58 \%$ \\
\hline Machine C & $55.9 \mathrm{~W}$ & $2.56 \%$ \\
\hline
\end{tabular}

\section{EXPERIMENTAL RESULTS}

To validate the proposed concept, a 400kVA generator equipped with a skew-less stator and a rotor with a modulated damper cage has been built in order to experimentally prove the proposed concept.

The 'new' rotor lamination of Machine $\mathrm{C}$ was manufactured in house, via an EDM process [20] and the laminations are shown in Fig. 10, where the pattern of the unconventionally displaced damper bars' holes can be observed. The test bench with the fully assembled machine (with a skew-less stator) can be observed in Fig. 11.
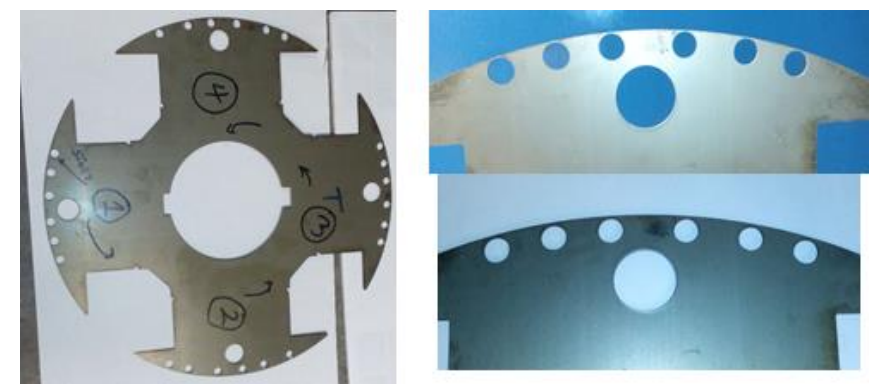

Fig. 10. Rotor lamination showing the modulated holes for the damping bars.

\section{A. Validation of the proposed concept: waveform analysis}

The purpose of this test is to confirm the design impact of the unconventionally displaced damper cage on the voltage waveform. This section therefore represents the core of this work, as it is aimed at confirming the validity of the proposed concept by demonstrating that a THD lower than 3\%, at noload operation, is achievable without implementing stator slot skew onto the $400 \mathrm{kVA}$ SG.

The experimental platform shown in Fig. 11 consists of an induction machine drive, acting as the prime mover, whose speed loop controls the frequency of the SG, which is mounted on the same shaft of the motor. The test is carried out on a cold machine to be coherent with the corresponding FE evaluation.

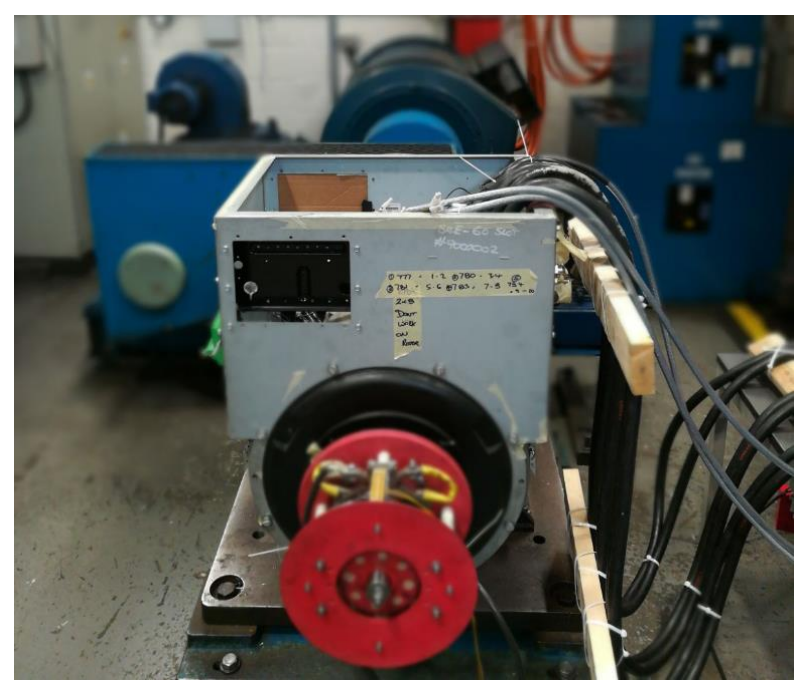

Fig. 11: Prototype test bench. 
The experimental results of the no-load line to line voltages are compared with the FE results in Fig. 12. An excellent match between numerical and experimental results can be observed. This is also confirmed by the comparison, shown in the same picture, between the THD of such output voltages, where the relevant error is $\approx 10 \%$. This proves the feasibility of the modulated damper cage concept for power quality improvement purposes. In fact, the study has demonstrated that this design technique is able to guarantee a THD $<3 \%$ without resorting to the skewing.

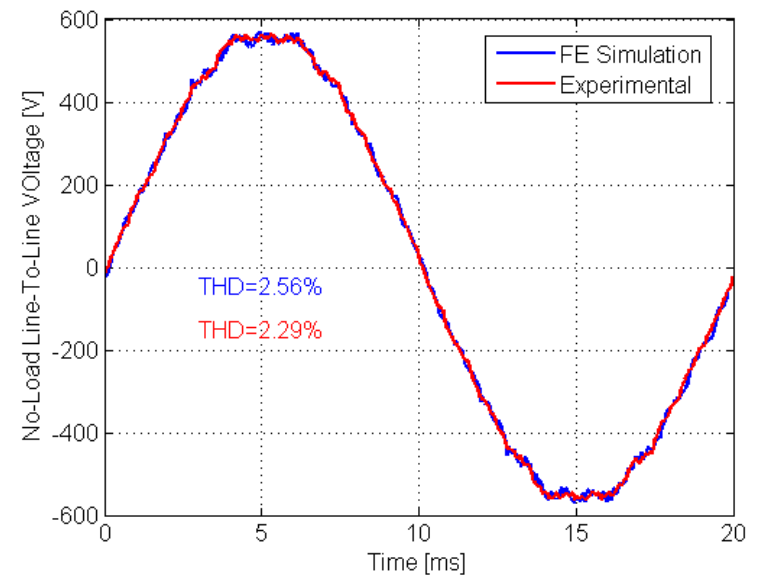

Fig. 12. No-load, line-to-line voltage waveforms: FE vs. experimental results.
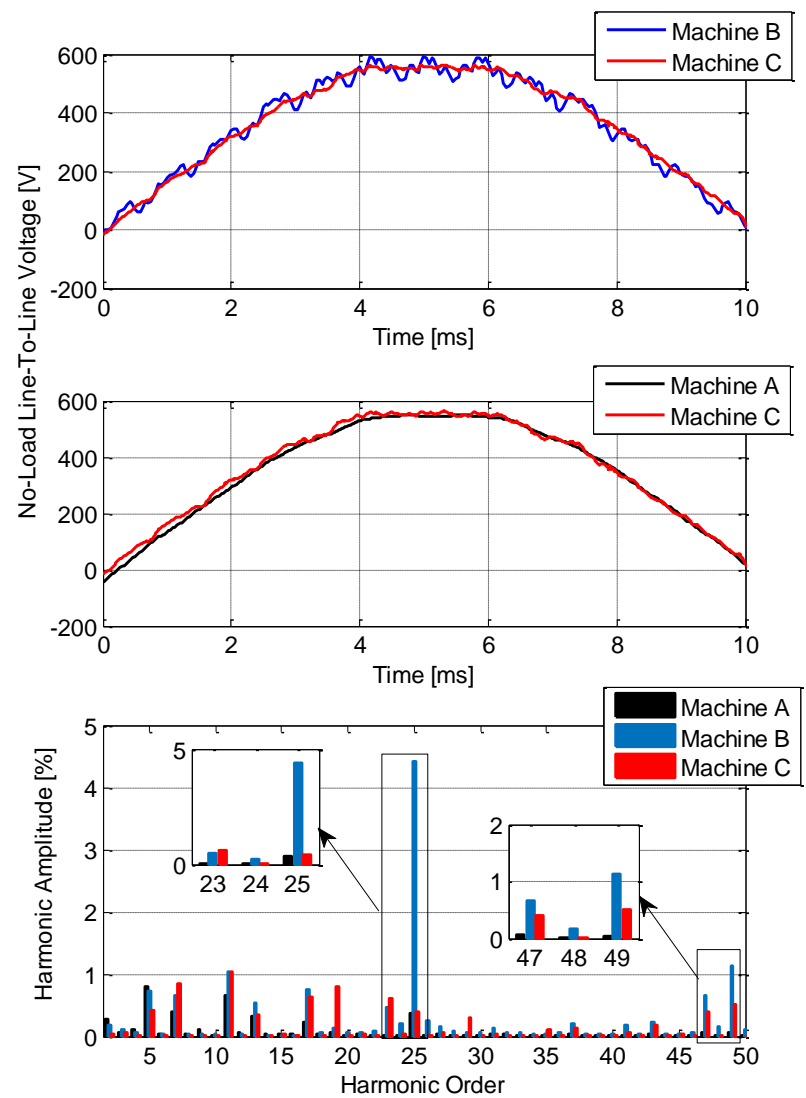

Fig. 13. No-load, line-to-line voltage: comparison between a) voltage waveforms of Machine $B$ and Machine $C, b)$ voltage waveforms of Machine A and Machine C, c) harmonic amplitude voltage spectra of the three machines.
For the sake of completeness, the measured voltage waveforms are compared with those relative to Machine A and Machine B. This comparison, shown in Fig. 13, confirms the results provided in Section VI.B (Table V), where it can be observed that

1) the THD improvement due to the modulated rotor with respect to the normal rotor is mainly due to the heavy attenuation of the first group of slotting harmonics;

2) the "cleaner" voltage shape of the benchmark machine with respect to the prototyped machine is obtained through the disruptive and costly technique of skewing.

It can be concluded that the results presented in this section confirm the validity of the GA-FE-based methodology aimed at finding an optimal damper cage topology. Having therefore found out that a skew-less configuration can still meet very stringent power quality requirements if combined with an optimal damper winding design, then in the next sections a comparison between the performance of the new prototype and the benchmark machine at no-load, short-circuit (SC), full-load and overload operations will be presented and discussed. For a fair judgement of the accuracy of the comparative results, it is important to note that the method used for machining the rotor laminations of Machine $\mathrm{C}$ (i.e. the EDM) is different from the standard stamping technology used to cut the laminations of the "off-the-shelf" Machine A. However, it is important to observe that main aim of the next sections is to prove that the new prototype does not affect the overall, steady-state and transient performance of the current generator. Therefore, the dissimilarities (in terms of mechanical stress on the materials, main dimensions, etc.) potentially ensuing from the different cutting methods should not influence the main achievement of the last part of this work.

\section{B. No-load Characteristic}

The investigation was carried out on a cold machine with the output terminal open-circuited, the automatic voltage regulator (AVR) disconnected and the field winding terminals directly connected to an external controllable DC supply. Slip rings, such as can be seen in Fig. 11 were used to record the main field winding voltage and current. The alternator was run at rated speed and the excitation increased in incremental steps. The line-to-line voltage vs. rotor field current is plotted and compared in Fig. 14 against the available experimental no-load curve relative to Machine A. It can be observed the perfect match between the two curves and, in particular, it is found that the new Machine $\mathrm{C}$ prototype achieves the rated voltage value with a field current reduced by $0.7 \%$ in comparison with the original Machine A.

\section{Short-circuit Characteristic}

This test is aimed at determining the excitation requirements and capabilities of the machine under test. Also, it is possible to determine the unsaturated synchronous reactance. As well as for the no-load characteristic, the SC curves of the new prototype and the benchmark machine are compared to prove that the new design does not affect 
negatively the performance. In Fig. 15, the excellent match between the characteristics can be observed, resulting in a very good match also in respect to the unsaturated synchronous reactance $(3.38 p . u$. for the new prototype against $3.35 p . u$. for the existing machine).

The investigation is carried out on a cold machine. A short circuit is applied to the generator's terminals. As well as for the no-load test, the AVR was disconnected and a DC supply was used. The generator was run at rated speed and then the excitation was increased in discrete steps until the output current was $50 \%$ above the rated value. At each step, the values of stator current, exciter field voltage and current and the generator field voltage and current (through the slip rings) were recorded. It was finally possible to plot the line current vs. the rotor field current figure shown above in comparison with the one available for the current alternator. The last step was that of evaluating the unsaturated synchronous reactance as the ratio of the excitation current required to sustain the rated SC current, to the excitation current required to sustain rated open circuit voltage. This second value is derived from the air gap line extrapolated from the no-load curve, as shown in Fig. 14, as this line represents the unsaturated excitation requirement.

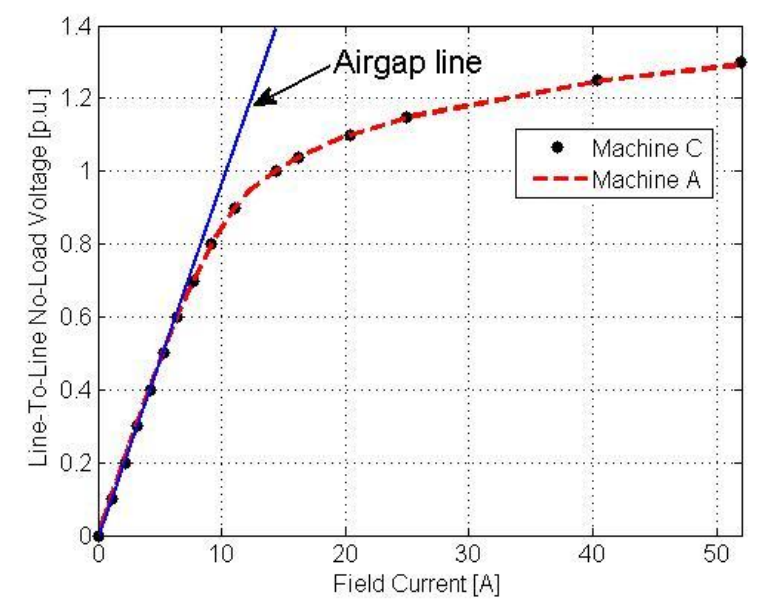

Fig. 14. No-load characteristics: experimental comparison between Machine A and Machine C.

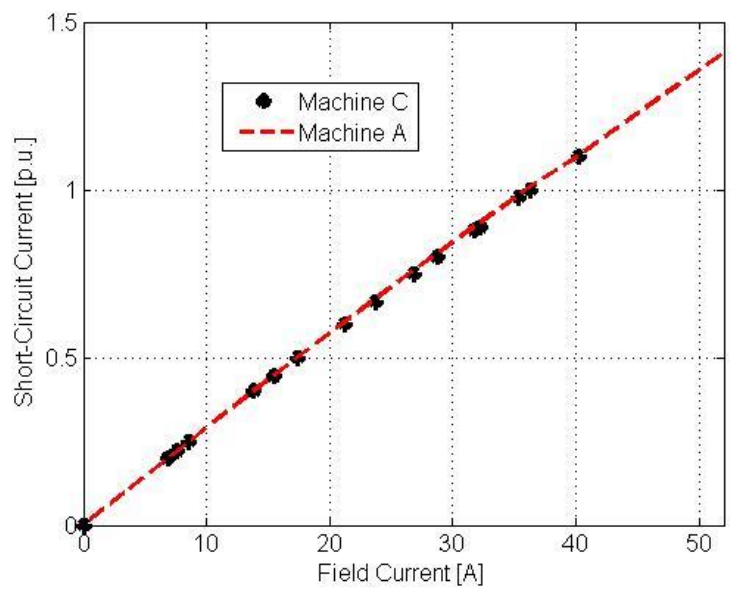

Fig. 15. SC characteristics: experimental comparison between Machine A and Machine C.

\section{Power Loss and Efficiency}

To determine the overall machine efficiency, the "summation of separate losses" method suggested by [21] for synchronous machines with electrical excitation was used. In particular, the no-load test performed as in Section VIII.B was used to record the shaft torque and thus to determine the shaft power. The constant losses were thus obtained as suggested in [21] and used to firstly extrapolate the windage and friction losses and then to determine the iron loss contribution. A rated full-load temperature test was carried out for the armature winding and the field winding losses. The excitation losses were added by assuming an efficiency of the exciter of $90 \%$ (i.e. excitation losses were taken equal to the $10 \%$ of the field winding loss). Although this is an approximation, given the comparative purposes of this section, it has to be noticed that both machines were equipped with the same excitation system, consisting of a typical brushless three-phase layout [17]. Finally, from the short-circuit test (with coupled machine) performed as in Section VIII.C, the additional losses were determined.

Table VI shows the comparison in terms of losses and efficiencies between the skew-less Machine $\mathrm{C}$ and the original Machine A. The excellent match between the machines' efficiencies prove that no significant performance deterioration has been generated. It is interesting to note that the loss reduction achieved by the optimal Machine $\mathrm{C}$ comes mainly from the field winding contribution, which results in a slight efficiency improvement (by $0.23 \%$ ). This is partially due to the positive effects (e.g. lower field current and lower rotor temperatures) resulting from the removed skewing and the modulated bar pattern.

TABLE VI

Comparison BetWeen Optimal AND EXISTING MACHINE - EFFICIENCY CALCULATION BY LOSS SUMMATION METHOD

\begin{tabular}{|c|c|c|}
\hline Loss Component & Machine C & Machine A \\
\hline Windage \& Friction & $2.387 \mathrm{~kW}$ & $2.141 \mathrm{~kW}$ \\
\hline Iron $(\mathrm{Fe})$ & $3.933 \mathrm{~kW}$ & $3.884 \mathrm{~kW}$ \\
\hline Armature Winding $(\mathrm{Cu})$ & $9.599 \mathrm{~kW}$ & $9.593 \mathrm{~kW}$ \\
\hline Field Winding $(\mathrm{Cu})$ & $4.993 \mathrm{~kW}$ & $5.433 \mathrm{~kW}$ \\
\hline Excitation & $0.493 \mathrm{~kW}$ & $0.544 \mathrm{~kW}$ \\
\hline Additional (Stray) & $2.450 \mathrm{~kW}$ & $3.111 \mathrm{~kW}$ \\
\hline Total & $23.855 \mathrm{~kW}$ & $24.706 \mathrm{~kW}$ \\
\hline Efficiency & $\mathbf{9 3 . 0 6 \%}$ & $\mathbf{9 2 . 8 3 \%}$ \\
\hline
\end{tabular}

\section{E. Dynamic Parameters}

One of the most important and critical aspect to consider for a comprehensive study of the renewed platform equipped with the unconventionally displaced damper cage, is related to its behavior during transient operations. The aim of this section is therefore that of proving that the new design does not modify the parameters corresponding to the generator SC performance. In order to determine these characteristic values, a suddenly applied three-phase SC test was performed. In this test, the alternator is coupled to a slave generator by a ring feeder coupling. A suitable DC power supply is connected to the exciter field winding and, after the generator is run at its rated speed and the output voltage is at its rated value, then it 
becomes possible to apply the three-phase SC. The dynamic parameters determination is performed according to the classical method described in [22] and the comparison between the existing and the novel prototype in terms of these quantities is summarized in Table VII. Here, some discrepancies between the results can be observed, mainly due to the different design features of the optimal Machine $\mathrm{C}$ against the benchmark Machine A. In fact, the absence of skew in Machine $\mathrm{C}$ can lead to a slightly decreased leakage inductance, while the modulated bar arrangement obviously results in a dissimilar behavior of the relevant currents. Also the field currents feeding the short-circuited armature winding is different between the two machines. However, given that the maximum error between the results summarized in Table VII is less than $10 \%$, it can be concluded that besides the overall performance of the machine, also the dynamic behavior of the generator remains almost unmodified.

TABLE VII

DYNAMIC PARAMETERS - COMPARISON OF EXPERIMENTAL RESULTS

\begin{tabular}{|c|c|c|c|c|}
\hline \multicolumn{2}{|l|}{ Dynamic Parameters } & Machine C & Machine A & Error \\
\hline Synchronous Reactance & $X_{d}$ & 2.40p.u. & 2.63p.u. & $8.75 \%$ \\
\hline Transient Reactance & $X_{d}^{\prime}$ & $0.122 p . u$. & 0.129p.u. & $5.74 \%$ \\
\hline Sub-transient Reactance & $X_{d}^{\prime \prime}$ & 0.083p.u. & 0.091p.u. & $8.79 \%$ \\
\hline Transient SC time constant & $T_{d}^{\prime}$ & $0.056 s$ & $0.062 s$ & $9.68 \%$ \\
\hline Sub-transient SC time constant & $T_{d}{ }^{\prime \prime}$ & $0.01226 s$ & $0.01299 s$ & $5.62 \%$ \\
\hline
\end{tabular}

Besides those on the efficiency and the dynamic performance, other important implications that the new damper cage pattern can have are related to the vibration and noise levels. Although the full description of the relevant tests goes beyond the main scope of this paper, it is worth to mention that no significant differences were registered between the two machines and that the vibration and noise levels are well below the standard limits indicated by [2].

\section{CONCLUSIONS}

This paper has shown the significant effect that damper windings can have on the operation but also on the manufacturing processes of wound-field, salient-pole SGs. An innovative damper cage scheme based on asymmetrically distributed bars was proposed and investigated. It was shown how, through the implementation of this unconventional, modulated bar displacement, the need for stator skewing can be removed without impacting the power quality requirements (related to the no-load voltage THD) and the overall machine efficiency and general performance.

The proposed concept has been experimentally validated on a full-scale prototype. The prototype achieved a THD equal to $2.29 \%$ and an improved efficiency of $0.23 \%$, while keeping the no-load, full-load and transient requirements the same as the existing alternator.

As a main outcome of not needing skew, from preliminary calculations (done in collaboration with a prominent SG manufacturer) it is predicted that, without the need for the skewing process, a prototype will get off the assembly line approximately in twenty minutes time less. This translates to a cost saving of approximately $5-8 \%$ per machine. The modulated damper cage, as proposed in this paper, therefore represents a fantastic opportunity to improve the market potential of these classical machines without compromising power quality and efficiency.

\section{REFERENCES}

[1] IEEE, 'IEEE Recommended Practice and Requirements for Harmonic Control in Electric Power Systems', 2014.

[2] BS EN 60034-22:2009, Rotating electrical machines. AC generators for reciprocating internal combustion (RIC) engine driven generating sets, Feb. 2010.

[3] D. Fallows, S. Nuzzo, A. Costabeber, M. Galea, "Harmonic reduction methods for electrical generation: a review," IET Generation, Transmission \& Distribution, vol. 12, no. 13, pp. 3107-3113, 2018.

[4] A. Spargo, S. Ilie, J. Chan, "Salient-pole rotor optimizations for synchronous generators using FEA software", 2017 IEEE Workshop on Electrical Machines Design, Control and Diagnosis (WEMDCD), pp. 158-162, 2017.

[5] A. Tessarolo, 'Accurate Computation of Multiphase Synchronous Machine Inductances Based on Winding Function Theory', IEEE Trans. Energy Convers., vol. 27, no. 4, pp. 895-904, Dec. 2012.

[6] Pyrhonen, J., Tapani, J., and Hrabovcovà, V. (2008). Design of Rotating Electrical Machines. Chicester, UK: John Wiley \& Sons, Ltd.

[7] M. P. Kostenko and L. M. Piotrovskiı̌, Electrical Machines. Creset, 1968.

[8] S. Nuzzo, M. Galea, C. Gerada, D. Gerada, A. Mebarki, N. L. Brown, "Damper cage loss reduction and no-load voltage THD improvements in salient-pole synchronous generators", $8^{\text {th }}$ IET International Conference on Power Electronics, Machines and Drives (PEMD 2016), pp . 1-7, 2016.

[9] A. Tessarolo, C. Bassi, and D. Giulivo, 'Time-Stepping Finite-Element Analysis of a 14-MVA Salient-Pole Shipboard Alternator for Different Damper Winding Design Solutions', IEEE Trans. Ind. Electron., vol. 59, no. 6, pp. 2524-2535, Jun. 2012.

[10] G. Traxler-Samek, R. Zickermann, and A. Schwery, 'Cooling Airflow, Losses, and Temperatures in Large Air-Cooled Synchronous Machines', IEEE Trans. Ind. Electron., vol. 57, no. 1, pp. 172-180, Jan. 2010.

[11] S. Nuzzo, M. Degano, M. Galea, C. Gerada, D. Gerada, N. Brown, "Improved Damper Cage Design for Salient-Pole Synchronous Generators", IEEE Trans. Ind. Electron., vol. 64, no. 3, pp. 1958-1970, 2017.

[12] S. Nuzzo, M. Galea, C. Gerada, N. Brown, "A fast method for modelling skew and its effects in salient-pole synchronous generators", IEEE Trans. Ind. Electron., vol. 64, no. 10, pp. 7679-7688, 2017.

[13] Y. Wang, G. Vakil, S. Nuzzo, M. Degano, M. Galea, C. Gerada, H. Zhang, N. Brown "Sensivitity analysis for performance and power density improvements in salient-pole synchronous generators", 2017 IEEE Workshop on Electrical Machines Design, Control and Diagnosis (WEMDCD), pp. 33-38, 2017.

[14] P. Bolognesi, "A mid-complexity analysis of long-drum-type electric machines suitable for circuital modelling", $200818^{\text {th }}$ International Conference on Electrical Machines, pp. 1-5, 2008.

[15] A. Biebighauser and A. Ghita, "Rotor for a rotating electrical machine," Patent WO 2014/202985 A2, Dec. 24, 2014.

[16] S. Nuzzo, P. Bolognesi, M. Galea, C. Gerada, "A hybrid analyticalnumerical approach for the analysis of salient-pole synchronous generators with a symmetrical damper cage", 2017 IEEE International Electric Machines and Drives Conference (IEMDC), pp. 1-8, 2017.

[17] S. Nuzzo, M. Galea, C. Gerada, N. Brown, "Analysis, modeling, and design considerations for the excitation systems of synchronous generators", IEEE Trans. Ind. Electron., vol. 65, no. 4, pp. 2996-3007, 2018.

[18] S. Poles, "MOGA-II An improved Multi-Objective Genetic Algorithm," Esteco, Trieste, Italy, Tech. Rep., 2003.

[19] T. Plazenet, T. Boileau, C. Caironi, B. Nahid-Mobarakeh, "A compprehensive study on shaft voltages and bearing currents in rotating machines," IEEE Trans. Ind. Appl., 2018 (Early Access). 
[20] E. C. Jameson, Electrical Discharge Machining, 2001.

[21] BS EN 60034-2-1:2014, Rotating electrical machines. Standard methods for determining losses and efficiency from test (excluding machines for traction vehicles), Sep. 2014.

[22] Guide for Test Procedures for Synchronous Machines Part I Acceptance and Performance Testing Part II-Test Procedures and Parameter Determination for Dynamic Analysis, IEEE Std. 115-2009, 2009 ..

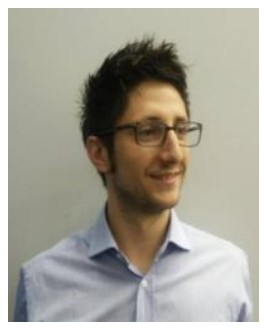

S. Nuzzo received the B. Sc. and M.Sc. degrees in electrical engineering from the University of Pisa, Pisa, Italy, in 2011 and 2014, respectively.

He received his Ph.D. degree in Electrical Machine Design in 2018 from the University of Nottingham, Nottingham, U.K, where he is currently working as a Research Fellow within the Power Electronics, Machines and Control (PEMC) Group.

His current research interests are the analysis, modelling and optimizations of electrical machines, with focus on salient-pole synchronous generators and brushless excitation systems for industrial power generation applications.

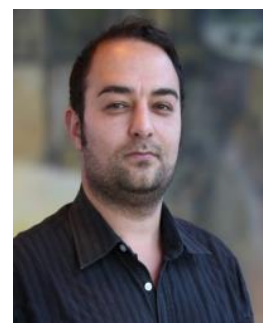

Michael Galea (M'13-SM'18) received the Ph.D. degree in electrical machines design from The University of Nottingham, Nottingham, U.K., in 2013.

$\mathrm{He}$ was a Research Fellow with The University of Nottingham, where he was also a Lecturer in electrical machines and drives within the Power Electronics, Machines and Control Group. He is currently the Head of School of Aerospace in the University of Nottingham, Ningbo, China. He currently lectures in Electrical Drives and in Aerospace Systems Integration and manages a number of diverse projects and programmes related to the more / all electric aircraft, electrified propulsion and associated fields. His main research interests are design, analysis and thermal management of electrical machines and drives (classical and unconventional), the more electric aircraft and electrified and hybrid propulsion.

Prof. Galea is a Fellow of the Royal Aeronautical Society and a Senior Member of the IEEE.

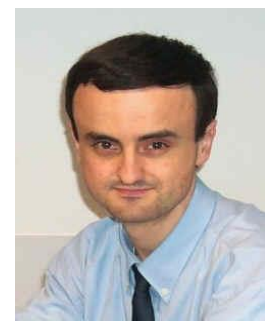

Paolo Bolognesi (M'99) eceived the M.Sc. and Ph.D. degrees in Electrical Engineering from the University of Pisa, Pisa, Italy, in 1995 and 1999, respectively.

He joined then the University of Pisa as a post-doc junior researcher and finally as a Senior Researcher and Appointed Professor since 2001

His research interest span from modelling, analysis and design of electromagnetic devices, including unconventional electrical machines and electromechanical actuators, to innovative topologies and modulation methods for static converters, also for applications related to electric and hybrid vehicles.

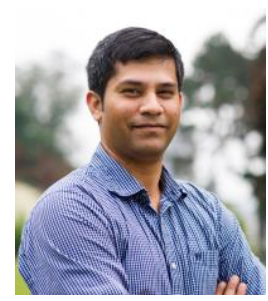

Gaurang Vakil (M'16) received the Ph.D. degree from Power Electronics, Machines and Drives (PEMD) group at Indian Institute of Technology - Delhi (IITD) in variable speed generator design for renewable energy applications in 2016. He subsequently worked as a Research Associate with the Power Electronics, Machines and Controls (PEMC) group at the University of Nottingham, UK.

In 2016 he was appointed as assistant professor within the electrical and electronics engineering department at the University of Nottingham.

His main research interests include design and development of high performance electrical machines for transport and propulsion, optimizing electric drive-train for pure electric and hybrid vehicles (aerospace and automotive), high power density machines and magnetic material characterization.

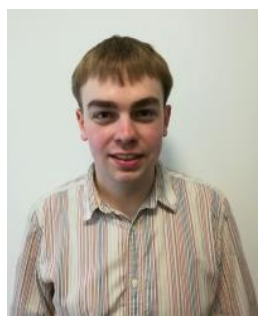

Daniel Fallows received the B.Sc. and the M.Sc. degrees from the University of Nottingham, UK, in 2015.

$\mathrm{He}$ is currently a PhD student within the Power Electronics, Machines and Control (PEMC) group at the University of Nottingham, where his special fields of interest include synchronous generator excitation systems and embedded computing. His employment experience includes working at Cummins Generator Technologies where he was involved with engineering software development and synchronous machine analysis.

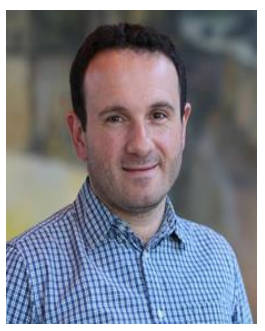

Chris Gerada (M'05-SM'12) received the Ph.D. degree in numerical modelling of electrical machines from The University of Nottingham, Nottingham, U.K., in 2005.

He was a Researcher with The University of Nottingham, working on high-performance electrical drives and on the design and modelling of electromagnetic actuators for aerospace applications. Since 2006, he has been the Project Manager of the GE Aviation Strategic Partnership. In 2008, he became a Lecturer in electrical machines, in 2011, as an Associate Professor, and in 2013, a Professor at The University of Nottingham. His main research interests include the design and modelling of highperformance electric drives and machines.

Prof. Gerada serves as an Associate Editor for the IEEE TRANSACTIONS ON INDUSTRY APPLICATIONS and is the Chair of the IEEE

Industrial Electronics Society Electrical Machines Committee.

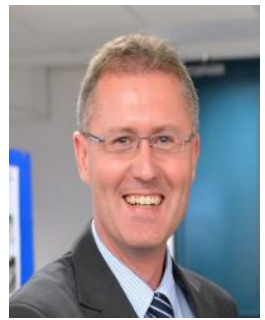

Neil Brown received the graduate degree in Electric/Electronic Engineering from Nottingham Trent University, Nottingham, U.K., in 1991, and received the Ph.D. degree in electrical machines from Durham University, Durham, U.K., in 2003. He is currently a Visiting Professor at The University of Nottingham, Nottingham, U.K.

He joined Cummins in 1995, and is the Chief Engineer Stamford Products, Cummins Generator Technologies, Stamford, U.K. While at Cummins, he has held various roles, including Applications Engineer, Electromagnetic Design Engineer, Research Manager, Chief Engineer for Stamford Products, Chief Engineer Research and Technology, and Director, Advanced Electrical Machines, before returning to his role as Chief Engineer Stamford Products in 2016.

Dr. Brown is the author of 90 publications, named inventor of 21 patents, and a Chartered Engineer and a Fellow of the Institution of Engineering and Technology, U.K. 